ORIGINAL RESEARCH

\title{
Oxidative Stress Status in Rats After Intermittent Exposure to Hypobaric Hypoxia
}

\author{
Santiago Esteva, PhD; Rafel Pedret, BSc; Nuria Fort, BSc; Joan Ramon Torrella, PhD; Teresa Pagès, PhD; \\ Ginés Viscor, PhD
}

From Departament de Fisiologia, Facultat de Biologia, Universitat de Barcelona, Barcelona, Spain.

\begin{abstract}
Objective.-Programs of intermittent hypobaric hypoxia (IHH) exposure are used to raise hemoglobin concentration and erythrocyte mass. Although acclimation response increases blood oxygen transport capacity leading to a $\mathrm{VO}_{2 \max }$ increase, the effects of reactive oxygen species (ROS) might determine the behavior of erythrocytes and plasma, thus causing a worse peripheral blood flow. The goals of the study were to establish the hematological changes and to discern whether an IHH protocol modifies the antioxidant/pro-oxidant balance in laboratory rats.

Methods.-Male rats were subjected to an IHH program consisting of a daily 4-hour session for 5 days/week until completing 22 days of hypoxia exposure in a hypobaric chamber at a simulated altitude of $5000 \mathrm{~m}$. Blood samples were taken at the end of the exposure period (H) and at $20(\mathrm{P} 20)$ and $40(\mathrm{P} 40)$ days after the end of the program, and compared to control $(\mathrm{C})$, maintained at sea-level pressure. Hematological parameters were measured together with several oxidative stress indicators: plasma thiobarbituric acid reactive substances (TBARS) and erythrocyte catalase (CAT) and superoxide dismutasc (SOD).

Results.-Red blood cell (RBC) count, hemoglobin concentration and hematocrit were higher in $\mathrm{H}$ group as compared to all the other groups $(p<0.001)$. However, there were no significant differences between the 4 groups in any of the oxidative stress-related parameters.

Conclusions.-The absence of significant differences between groups indicates that our IHH program has little impact on the general redox status, even in the laboratory rat, which is more sensitive to hypoxia than humans. We conclude that IHH does not increase oxidative stress.
\end{abstract}

Key words: intermittent hypoxia, hypobaric chamber, oxidative stress, free radicals, red blood cells

\section{Introduction}

Both intermittent and continuous hypoxia have gained popularity as a way to enhance aerobic capacity, and an increasing number of elite athletes use these strategies in combination with training programs. ${ }^{1-3}$ The most remarkable effects of high altitude on human physiology are due to the low oxygen partial pressure of the inspired air, and, consequently, several adjustments are needed to improve the delivery of oxygen to tissues. ${ }^{4}$ Acute hypoxia causes an immediate hyperventilation $^{5}$ and also raises erythropoietin levels, ${ }^{6}$ which elicits the increase in hemoglobin concentration

Corresponding author: Ginés Viscor, PhD, Departament de Fisiologia, Facultat de Biologia, Universitat de Barcelona, Av. Diagonal, 645, E-08028 Barcelona, Spain (e-mail: gviscor@ub.edu). and hematocrit. ${ }^{7,8}$ Hypoxia exposure also alters the redox balance through increased reactive oxygen species (ROS) production. ${ }^{9-12}$ A more prolonged exposure modifies the structure and functioning of skeletal muscle, ${ }^{13-15}$ and induces acid-base alterations that affect the affinity of hemoglobin for oxygen. ${ }^{16}$ Moreover, long-term exposure to hypobaric hypoxia also induces physical deterioration, which increases with altitude. ${ }^{17}$ This is reflected in a marked decrease in body weight, due in part to a reduction in muscle mass. ${ }^{18}$ Also, due to the increase in red cell mass, the apparent viscosity of blood can be increased with the possibility of a subsequent reduction in oxygen transport capacity. Other circulatory complications such as deep venous thrombosis cannot be ruled out in the presence of abnormally high hematocrit, although compensatory mechanisms have been described that 
can reduce the effective hematocrit after intense exercise. ${ }^{19}$ Prolonged exposure to high altitude in nonnative residents or recent altitude populations at a biological time scale often induces a complex syndrome: chronic mountain sickness. ${ }^{9,20,21}$ To prevent the negative effects of chronic hypoxia exposure, several procedures that alternate short hypoxia exposure with immediate recovery in normoxia have been proposed. ${ }^{3,22,23}$ These intermittent hypoxia-exposure protocols have revealed that such hypoxic stimulus can elicit an erythropoietic and other nonerythropoietic physiological adjustments that also affect aerobic capacity. Thus, these exposure protocols have been considered as efficient methods for high altitude acclimatization. ${ }^{8,24-26 .}$

Low levels of oxygen produce an increase in ROS. ${ }^{11,27-29}$ These molecules are crucial for the maintenance of oxygen homeostasis. ROS are abundantly formed during exercise and hypoxia and can serve as signaling molecules that help to maintain homeostasis. ${ }^{9,30}$ High levels of reactive oxygen species might increase lipid peroxidation with a subsequent production of malondialdehyde (MDA). During hypoxic stress, the insufficient delivery of oxygen to working muscles causes increased ROS production that may damage the polyunsaturated fatty acids in cell membrane structures. ${ }^{31}$ Cell membrane reduces its fluidity, permeability, and excitability and alters the function of membrane-bound enzymes. In cells with decreased membrane fluidity, the membrane fails to maintain tonic gradients. $^{32,33}$ This phenomenon has been related with the development of neurological sequelae associated with acute mountain sickness. ${ }^{34}$ An elaborate defense system providing various degrees of protection to cells against free radicals has evolved in all species. Various components of this protective system are increased in tissues or organs following exposure to extreme physiological conditions such as exercise training or altitude acclimation. ${ }^{31,35,36}$ Two intraerythrocytic enzymes, catalase (CAT) and superoxide dismutase (SOD), provide a primary defense line against ROS generated during hypoxic exposure.

This article completes a series of previous studies performed in our laboratory concerning peripheral oxygen delivery to muscle tissue and blood rheology after intermittent hypobaric hypoxia $(\mathrm{IHH}) .{ }^{15,37,38} \mathrm{In}$ the present paper, the evolution of hematological and oxidative stress parameters were analyzed at the end of an IHH exposure protocol to laboratory animals and after a recovery period. The goals of the study were to establish the hematological changes and to discern whether an IHH protocol (using hypobaric hypoxia, $5000 \mathrm{~m}$ ) modifies the antioxidant/pro-oxidant balance in laboratory rats.

\section{Materials and Methods}

\section{ANIMALS}

A total of 67 male Sprague-Dawley rats aged 6 weeks at the beginning of the experiment were randomly divided into 4 groups. The first experimental group of 18 rats (named $\mathrm{H}$, for hypoxic) were submitted to a program of IHH (described in detail later), and blood was drawn at the end of this program. The second and third experimental groups of 13 and 14 rats, respectively, were simultaneously submitted to the same program, but blood samples were obtained 20 and 40 days after the end of the protocol, being named group P20 and group P40 for the corresponding posthypoxia days. Finally, 22 rats were used as a triple control group (group C). Control animals were maintained in parallel under the same conditions as the 3 experimental groups. Samples from 9 of the controls (group C1) were obtained at the same time as those from $\mathrm{H}$, samples from 9 of the controls (group C2) were obtained at the same time as those from P20, and finally, samples from the 4 remaining controls (C3) were taken at the same time as those from P40.

This study was a part of a general procedure for studying peripheral gas exchange and blood rheology; thus all rats were killed and also used to provide other organ and tissues samples.

\section{HYPOBARIC CHAMBER AND INTERMITTENT HYPOBARIC HYPOXIA (IHH) PROGRAM}

A hypobaric chamber was used to submit the rats to the IHH program. The total volume of the hypobaric chamber was approximately $450 \mathrm{~L}$, which allowed the housing of 3 rat cages. The chamber walls were made of transparent polymethyl methacrylate acrylic plastic, thus facilitating the observation of animals during protocol application. A negative pressure gradient was produced inside the hypobaric chamber by means of a rotational vacuum pump (TRIVAC D5E, Leybold, Köln, Germany) by regulating the air flow rate at the inlet with a micrometric valve. Inner pressure was controlled by 2 differential pressure sensors (ID 2000, Leybold, Köln, Germany) connected to a vacuum controller (Combivac IT23, Leybold, Köln, Germany) driving a diaphragm pressure regulator (MR16, Leybold, Köln, Germany). Depending on the simulated altitude to be reached, a low-pressure set point was established in a control system. After the desired level was reached, the internal barometric pressure of the chamber was regulated and maintained by the vacuum control element.

After 2 weeks' quarantine, the animals were moved into the conditioned room containing the hypobaric chamber. An initial period of 5 days, free of disturbance, 
was established for complete habituation. The IHH program consisted of 4-hour sessions 5 days a week for 4 weeks and 2 additional days, thus completing 22 days of exposure to hypoxia ( 88 hours in total). The simulated altitude reached during each session was $5000 \mathrm{~m} \mathrm{(400}$ $\mathrm{mmHg}=533 \mathrm{hPa}$ ), which is equivalent to $11 \%$ oxygen at normobaric hypoxia. The control group was subjected to the same procedure, although the cages were installed above the hypobaric chamber rather than inside it.

\section{BLOOD SAMPLING PROCEDURE}

Blood samples were collected by cardiac puncture. Before extraction, animals were anesthetized with urethane $(1.5 \mathrm{~g} / \mathrm{kg} \mathrm{BM})$. Sodium heparin was used as anticoagulant. A fraction of each blood sample was separated for immediate hematological analysis, which was always completed within 10 minutes of blood withdrawal. A second portion of the sample was centrifuged at $1000 \mathrm{~g}$ for $10 \mathrm{~min}$ at $4^{\circ} \mathrm{C}$ to separate the cells from plasma for analysis. These 2 blood parts were then processed for storage at $-80^{\circ} \mathrm{C}$. The erythrocyte pellet was frozen in nonheparinized $5 \mathrm{~mL}$ tubes, and $1 \mu \mathrm{L}$ of a butylated hydroxytoluene (BHT) solution at a concentration of 1 $\mathrm{mmol} / \mathrm{L}$ in methanol was added for each milliliter of cell homogenate to prevent peroxidation amplification during sample storage. Plasma was also frozen in heparinized 5 $\mathrm{mL}$ tubes.

Before analysis of the oxidative stress parameters, both red blood cells (for SOD and CAT analysis) and plasma for thiobarbituric acid reactive substances (TBARS) were defrosted at room temperature.

\section{HEMATOLOGY AND OXIDATIVE STRESS-RELATED PARAMETERS}

The following hematological parameters were measured using an electronic cell counter (Celltac-alpha, Nihon Kohden Corp., Tokyo, Japan): red blood cell count (RBC), hemoglobin concentration $(\mathrm{Hb})$, hematocrit $(\mathrm{Hc})$, mean corpuscular volume (MCV), mean corpuscular hemoglobin $(\mathrm{MCH})$, mean corpuscular hemoglobin concentration (MCHC), and total white blood cell count (WBC).

The parameters of lipid peroxidation and antioxidant enzymatic activity measured were TBARS, CAT, and SOD, respectively. TBARS is widely used to quantify the lipid peroxidation caused by high ROS levels. The concentration of TBARS was measured in plasma as a product of lipid peroxidation following Yagi. ${ }^{39}$ This technique is based on the quantification of malondialdehyde (MDA) produced by lipoperoxidation that reacts with the thiobarbituric acid. A Labsystems iEMS Reader
MF (Finland) and Genesis Labsystems version 2.16 software were used. Results are expressed as nmols TBARS/mL plasma compared to a standard obtained by acid hydrolysis of tetraethoxypropane.

Catalase (CAT) contributes to the detoxification of $\mathrm{H}_{2} \mathrm{O}_{2}$ and its conversion to other less hazardous products. ${ }^{40,41}$ Its activity was determined in the erythrocyte hemolyzate following Aebi, ${ }^{42}$ by monitoring the $\mathrm{H}_{2} \mathrm{O}_{2}$ consumption at $240 \mathrm{~nm}$ with an Spectronic Genesys 2 spectrophotometer (Milton Roy Company, USA). Results are expressed as $k / \mathrm{g} \mathrm{Hb}$.

Superoxide dismutase ( $\mathrm{Cu}, \mathrm{Zn}-\mathrm{SOD})$ is one of the main detoxification enzymes in the cell. ${ }^{31}$ Superoxide $\left(\mathrm{O}_{2}{ }^{-}\right)$, which is the product on the first step of the Haber-Weiss reaction, is one of the most dangerous ROS in the cell. ${ }^{41}$ This enzyme was assayed in the hemolysate by the inhibition of pyrogallol autoxidation, due to the concentration of SOD in the cell. ${ }^{43}$ The product concentration was measured at $414 \mathrm{~nm}$ using a Labsystems iEMS Reader MF (Finland) and a Genesis Labsystems version 2.16 software, and is expressed as arbitrary units of $\mathrm{SOD} / \mathrm{g} \mathrm{Hb}$.

\section{STATISTICS}

Data for all the parameters are expressed as the sample mean \pm standard error of the mean. Comparisons between the experimental and control groups were analyzed by one-way ANOVA test. Afterwards, a multiple comparison test using the Scheffé procedure was run to determine the differences between each pair of experimental and control conditions. Descriptive statistics and analyses of normality were made with SigmaStat software package, whereas one-way ANOVA and Scheffé tests were performed by the application of suitable subroutines from SPPS/PC + package (SPSS Inc). Differences were considered statistically significant for $p<$ 0.05 .

\section{Results}

Normal growth was not affected by IHH, as reflected in body weight changes during the protocol. Moreover, no significant differences were found between $\mathrm{C} 1, \mathrm{C} 2$, or C3 for any of the parameters and, unless otherwise indicated, these 3 control groups were combined for all figures and tables and named Group C (see Figure 1).

\section{HEMATOLOGICAL PARAMETERS}

Hematological parameters for the 3 species are given in Table 1. ANOVA and Scheffé tests showed significant differences between the 4 experimental groups in most of 


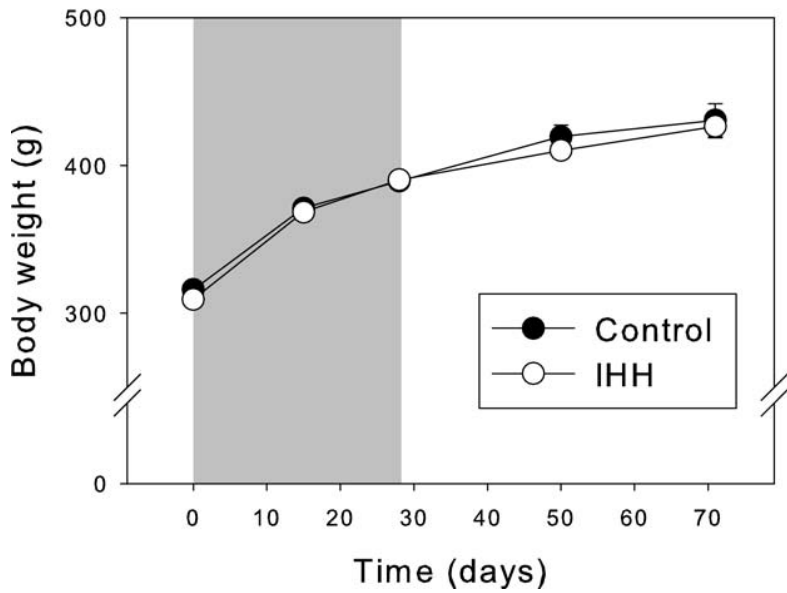

Figure 1. Rat body mass comparison between control animals (solid circles) and those submitted to the intermittent hypobaric hypoxia (IHH) program (open circles). The grey area indicates the IHH exposure period. Mean values $\pm \mathrm{SE}$ are indicated.

the hematological parameters. Hematological changes after exposure to hypobaric hypoxia were characterized by a significant increase in erythrocytes in the hypoxic group (H vs. C, $\mathrm{P} 20$, and $\mathrm{P} 40 ; p<0.001$ ), hematocrit ( $\mathrm{H}$ vs. $\mathrm{C}, \mathrm{P} 20$, and $\mathrm{P} 40 ; p<0.001)$, and hemoglobin concentration ( $\mathrm{H}$ vs. $\mathrm{C}, \mathrm{P} 20$, and $\mathrm{P} 40 ; p<0.001$ ). In addition, significant differences in the hematological indexes MCV and MCH were found; they were slightly increased in the $\mathrm{H}$ group and later returned to basal levels (see Table 1). A higher level in WBC count was observed also in $\mathrm{H}$ group, thus indicating a possible inflammatory state that was completely reverted in P40 group.

\section{OXIDATIVE STRESS-RELATED PARAMETERS}

Data of oxidative stress-related indicators are plotted in Figure 2. No significant differences were observed in the three parameters studied (TBARS, CAT, and SOD) when the 4 experimental groups where compared, although a slight trend is observed in TBARS results (increased values for $\mathrm{H}$ compared to the other groups).

\section{Discussion}

Many studies have reported that chronic hypoxia induces deleterious effects on body mass. ${ }^{44,45}$ A recent experimental study of chronic IHH in rats with an alternating schedule of $4 \times 4$ and $2 \times 2$ days of sea level and simulated $4600 \mathrm{~m}$ altitude demonstrated a severe body weight reduction and compromised survival rate, ${ }^{46}$ probably due to the severe hypophagia induced by hypoxia. ${ }^{47}$ However, possibly due to the lower duration of daily hypoxia exposure, in the present study we detected no negative effects on normal growth rate. This indicates that our hypoxia exposure regime is compatible with the standard living conditions of these experimental animals.

\section{HEMATOLOGICAL PARAMETERS}

The hematological parameters and oxygen transport indexes for the 4 experimental groups were within the range of the results previously found in rats ${ }^{46}$ and humans. ${ }^{48,49}$ The most remarkable adaptations to the acclimation program are those observed in the hematological profile. The significant increases in red blood cells, hematocrit, and hemoglobin concentration values in group $\mathrm{H}$ are clearly associated with an enhancement of blood oxygen transport capacity. After the exposure period was over, the elevated values of $\mathrm{RBC}, \mathrm{Hb}$, and $\mathrm{Hc}$ tended to return to the lower, normal range. Consequently, it seems clear that intermittent exposure to hypoxia can also stimulate erythropoiesis in the rat to the same extent as chronic exposure. ${ }^{50-52}$ Slight differences in hematologic

Table 1. Hematological parameters for the different groups of experimental animals

\begin{tabular}{|c|c|c|c|c|c|}
\hline & & $C(n=17)$ & $H(n=10)$ & $P 20(n=13)$ & $P 40(n=14)$ \\
\hline $\mathrm{RBC}\left(\right.$ cells $\left.\times 10^{6} / \mu \mathrm{L}\right)$ & $\mathrm{a}$ & $8.81 \pm 0.10$ & $9.98 \pm 0.20 * * *$ & $8.91 \pm 0.16$ & $8.60 \pm 0.14$ \\
\hline $\mathrm{Hb}(\mathrm{g} / \mathrm{L})$ & $\mathrm{a}$ & $15.66 \pm 0.19$ & $18.75 \pm 0.37 * * *$ & $16.26 \pm 0.28$ & $15.56 \pm 0.25$ \\
\hline Hc $(\%)$ & $\mathrm{a}$ & $47.03 \pm 0.66$ & $55.22 \pm 1.02 * * *$ & $48.09 \pm 0.79$ & $47.03 \pm 0.77$ \\
\hline $\operatorname{MCV}\left(\mu \mathrm{m}^{3}\right)$ & $\mathrm{b}$ & $53.33 \pm 0.41$ & $55.25 \pm 0.37 *$ & $53.86 \pm 0.50$ & $54.72 \pm 0.44$ \\
\hline $\mathrm{MCH}(\mathrm{pg})$ & $\mathrm{c}$ & $17.77 \pm 0.12$ & $18.76 \pm 0.15 * *$ & $18.03 \pm 0.85$ & $17.92 \pm 0.20$ \\
\hline $\operatorname{MCHC}(\%)$ & & $33.34 \pm 0.17$ & $33.96 \pm 0.16$ & $33.90 \pm 0.21$ & $33.09 \pm 0.23$ \\
\hline WBC $\left(\right.$ cells $\left.\times 10^{3} / \mu \mathrm{L}\right)$ & $\mathrm{d}$ & $9.85 \pm 0.83$ & $13.50 \pm 1.47 *$ & $12.61 \pm 0.65$ & $9.40 \pm 0.78$ \\
\hline
\end{tabular}

Mean values and standard errors are indicated. Significant differences between groups are indicated by the following code: (a) $\mathrm{H}$ vs. all other groups, (b) $\mathrm{C}$ vs. H, (c) H vs. C and P40, (d) H vs. P40. Levels of significance are indicated by asterisks as: $* p<0.001, * * p<0.01$, or $* * * p<0.05$.

$\mathrm{C}$, control group; H, hypoxic group; P20, post-20 days group; P40, post-40 days group; RBC, red blood cell count; Hb, hemoglobin concentration; Hc, hematocrit; $\mathrm{MCV}$, mean corpuscular volume; $\mathrm{MCH}$, mean corpuscular hemoglobin; MCHC, mean corpuscular hemoglobin concentration; WBC, white blood cell count. 

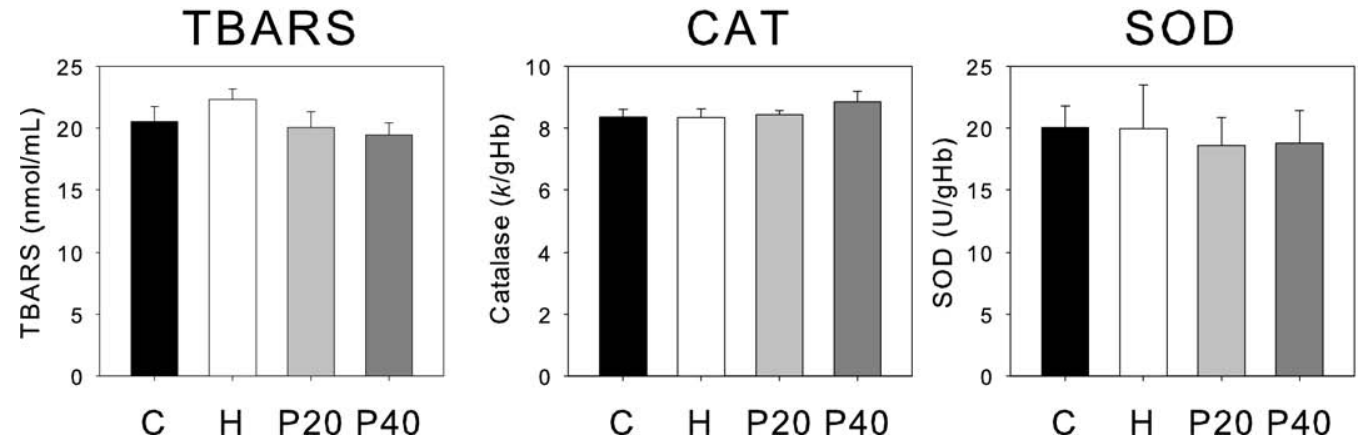

Figure 2. Oxidative stress markers for the 4 groups of experimental animals: C (black), H (white), P20 (light grey), and P40 (dark grey). Mean values and standard errors are indicated. Panels: TBARS, Thiobarbituric acid reactive substances; CAT, Catalase; SOD, Superoxide dismutase.

indexes may be due to the influence of a significantly higher percentage of reticulocytes in group $\mathrm{H}$ rats, which would cause a small increase in mean erythrocyte volume. ${ }^{8,53}$ The elevated leukocyte counts in $\mathrm{H}$ group animals can be considered as a possible sign of an underlying inflammatory response to the hypoxic stress.

\section{OXIDATIVE STRESS-RELATED PARAMETERS}

Results obtained for oxidative stress-related indicators in the 4 experimental groups after IHH can be considered positive for all possible future applications of this kind of protocol. Some authors report that oxidative stress-related indicators were increased after acute hypoxia exposure. ${ }^{11,54,55}$ Although our results do not show any significant differences in the three parameters studied (TBARS, CAT, and SOD), we observed a trend in TBARS levels in the $\mathrm{H}$ groups.

Polyunsaturated fatty acids (PUFAs) range among the molecules most susceptible to ROS. One possible explanation for a rise in lipid peroxidation after the cessation of hypoxia is the increased susceptibility to ROS of unsaturated fatty acids. This is because hypoxia, like intense exercise, markedly increases the concentration and the degree of unsaturation of nonesterified fatty acids in blood. ${ }^{31,56,57}$ Many studies have provided evidence for substantial increases in plasma lipid-peroxidation levels after aerobic exercise, ${ }^{40,58,59}$ although others have reported no change. ${ }^{60,61}$ Moreover, although there are some reservations about the validity of the TBARS assay in detecting lipid peroxidation in vivo, since it is not specific to malondialdehyde and lipid peroxidation is not the only source of malondialdehyde, it is still widely used for this purpose.

CAT protects the cells from the toxic effects of hydrogen peroxide by catalyzing its decomposition to water without free radical production. SOD provides the first line of defense against oxidative stress by catalyzing the dismutation of superoxide to hydrogen peroxide. CAT and SOD did not show significant differences between experimental groups, which indicates that IHH did not affect the activities of these enzymes either. Several studies on different conditions of hypoxia have demonstrated that an abnormal increase in the production of ROS has an important role in the defense against oxidative stress. This increase would facilitate antioxidant gene expression and so reduce the subsequent cell damage. $^{62,63}$ The amount, intensity, and type of exercise might be related to the extent of lipid peroxidation, the previous training state being more important than the type of exercise. ${ }^{61}$

Our study has some limitations. We studied oxidative stress markers from a general descriptive approach, because abundant information has been accumulated on the oxidative stress generated in response to acute hypoxia. However, a more detailed study of redox status during hypoxia exposure and in the hours following each acclimatization session might be much more informative. Further studies, perhaps including other mammalian species, would be helpful to clarify this point.

In conclusion, after a program of intermittent hypobaric hypoxia in rats, blood and plasma oxidative stressrelated markers offered no evidence of a significant imbalance in redox status. This finding argues in favor of the use of intermittent hypobaric hypoxia protocols in several well established applications-such as altitude preacclimation and athletic performance improvementand for other potential future purposes in certain pathological states.

\section{Acknowledgments}

The authors thank Robin Rycroft (Language Advisory Service-U.B.) for his help in editing the manuscript. 


\section{Ethical Approval}

The present study was authorized by the University of Barcelona's Ethical Committee for Animal Experimentation and ratified, in accordance with current Spanish legislation, by the Departament de Medi Ambient i Habitatge (file \#1899) of the Catalonia Government (Generalitat de Catalunya).

\section{References}

1. Levine BD, Stray-Gundersen J. "Living high-training low": effect of moderate-altitude acclimatization with low altitude training on performance. J Appl Physiol. 1997;83: 102-112.

2. Wilber RL. Altitude Training and Athletic Performance. Champaign, IL: Human Kinetics; 2004.

3. Robach P, Schmitt L, Brugniaux JV, et al. Living high-training low: effect on erythropoiesis and maximal aerobic performance in elite Nordic skiers. Eur J Appl Physiol. 2006;97:695-705.

4. Leon-Velarde F, Gamboa A, Chuquiza JA, et al. Hematological parameters in high altitude residents living at 4,355, 4,660, and 5,500 meters above sea level. High Alt Med Biol. 2000;1:97-104.

5. West JB. Acclimatization and tolerance to extreme altitude. J Wilderness Med. 1993;4:17-26.

6. Eckardt KU, Boutellier U, Kurtz A, et al. Rate of erythropoietin formation in humans in response to acute hypobaric hypoxia. J Appl Physiol. 1989;66:1785-1788.

7. Ferretti G, Boutellier U, Pendergast DR, et al. Oxygen transport system before and after exposure to chronic hypoxia. Int J Sports Med. 1990;11(suppl 1):S15-S20.

8. Rodriguez FA, Casas H, Casas M, et al. Intermittent hypobaric hypoxia stimulates erythropoiesis and improves aerobic capacity. Med Sci Sports Exerc. 1999;31:264-268.

9. Xing G, Qualls C, Huicho L, et al. Adaptation and maladaptation to ambient hypoxia; Andean, Ethiopian and Himalayan patterns. PLOS One. 2008;3:e2342.

10. Bakonyi T, Radak Z. High altitude and free radicals. J. Sports Sci Med. 2004;3:64-69.

11. Magalhães J, Ascensão A, Viscor G, et al. Oxidative stress in humans during and after 4 hours of hypoxia at a simulated altitude of 5500 m. Aviat Space Environ Med. 2004; 75:16-22.

12. Marin-Corral J, Fontes CC, Pascual-Guardia S, et al. Redox balance and carbonylated proteins in limb and heart muscles of cachectic rats. Antioxid Redox Signal. 2010;12: 365-380.

13. Ferretti G, Hauser H, Di Prampero PE. Maximal muscular power before and after exposure to chronic hypoxia. Int J Sports Med. 1990;11(suppl 1):S31-S34.

14. Hoppeler H, Kleiner E, Schlegel C, et al. Morphological adaptations of human skeletal muscle to chronic hypoxia. Int J Sports Med. 1990;11(suppl 1):S3-S9.

15. Panisello P, Torrella JR, Esteva S, Pages T, Viscor G. Capillary supply, fibre types and fibre morphometry in rat tibialis anterior and diaphragm muscles after intermittent exposure to hypobaric hypoxia. Eur J Appl Physiol. 2008;103:203-213.

16. Cerretelli P, Samaja M. Acid-base balance at exercise in normoxia and in chronic hypoxia: revisiting the "lactate paradox." Eur J Appl Physiol. 2003;90:431-448.

17. Kayser B. Factors Limiting Exercise Performance in Man at High Altitude [dissertation]. Geneva, Switzerland: Université de Genève; 1994.

18. Terrados N. Altitude training and muscular metabolism. Int J Sports Med. 1992;13(suppl 1):S206-S209.

19. Reinhart WH, Staubli M, Straub PW. Impaired red cell filterability with elimination of old RBC during a $100 \mathrm{~km}$ race. J Appl Physiol. 1983;54:827-830.

20. Leon-Velarde F, Maggiorini M, Reeves JT, et al. Consensus statement on chronic and subacute high altitude diseases. High Alt Med Biol. 2005;6:147-157.

21. Rivera-Chira M, Leon-Velarde F, Huicho L. Treatment of chronic mountain sickness: critical reappraisal of an old problem. Respir Physiol Neurobiol. 2007;158:251-265.

22. Brugniaux JV, Schmitt L, Robach $P$, et al. Living high-training low: tolerance and acclimatization in elite endurance athletes. Eur J Appl Physiol. 2006;96:66-77.

23. Pialoux V, Mounier R, Rock E, et al. Effects of the "live high-train low" method on prooxidant/antioxidant balance on elite athletes. Eur J Clin Nutr. 2009;63:756-762.

24. Wagner PD, Sutton JR, Reeves JT, et al. Operation Everest II: pulmonary gas exchange during a simulated ascent of Mt. Everest. J Appl Physiol. 1987;63:2348-2359.

25. Sutton JR, Reeves JT, Wagner PD, et al. Operation Everest II: oxygen transport during exercise at extreme simulated altitude. J Appl Physiol. 1988;64:1309-1321.

26. Richalet JP, Bittel J, Herry JP, et al. Use of a hypobaric chamber for pre-acclimatization before climbing Mount Everest. Int J Sports Med. 1992;13(suppl 1):S216-S220.

27. Moller P, Loft S, Lundby C, Olsen NV. Acute hypoxia and hypoxic exercise induce DNA strand breaks and oxidative DNA damage in humans. FASEB J. 2001;7:1181-1186.

28. Askew EW. Work at high altitude and oxidative stress: antioxidant nutrients. Toxicology. 2002;180:107-119.

29. Subudhi AW, Jacobs KA, Hagobian TA, et al. Antioxidant supplementation does not attenuate oxidative stress at high altitude. Aviat Space Environ Med. 2004;75:881-888.

30. Bailey DM, Davies B, Young IS. Intermittent hypoxic training: implications for lipid peroxidation induced by acute normoxic exercise in active men. Clin Sci. 2001;101: 465-475.

31. Metin G, Atukeren P, Alturfan AA, et al. Lipid peroxidation, erythrocyte superoxide-dismutase activity and trace metals in young male footballers. Yonsei Med J. 2003;44: 979-986.

32. Davies KJ, Quintanilha AT, Brooks GA, Packer L. Free radicals and tissue damage produced by exercise. Biochem Biophys Res Commun. 1982;107:1198-1205.

33. Vladimirov YA. Free radical lipid peroxidation in biomembrenes: mechanism, regulation and biological consequences. In: Johnson J, ed. Free Radicals, Aging, and 
Degenerative Disease. New York: Alan R Liss, Inc; 1986:141-195.

34. Bailey DM, Kleger GR, Holzgraefe M, Ballmer PE, Bartsch P. Pathophysiological significance of peroxidative stress, neuronal damage, and membrane permeability in acute mountain sickness. J Appl Physiol. 2004;96: 1459-1463.

35. Allesio HM, Goldfarb AH. Lipid peroxidation and scavenger enzymes during exercise: adaptive response to training. J Appl Physiol. 1988;64:1333-1336.

36. Ji LL, Stratman FW, Lardy HA. Enzymatic down regulation with exercise in rat skeletal muscle. Arc Biochem Biophys. 1988;263:137-149.

37. Esteva S, Panisello P, Torrella JR, Pagès T, Viscor G. Blood rheology adjustments in rats after a program of intermittent exposure to hypobaric hypoxia. High Alt Med Biol. 2009;10:275-281.

38. Esteva S, Panisello P, Torrella JR, Pagès T, Viscor G. Enzyme activity and myoglobin concentration in rat myocardium and skeletal muscles after passive intermittent simulated altitude exposure. J Sports Sci. 2009;27: 633-640.

39. Yagi K. Assay for blood plasma or serum. Methods Enzymol. 1984;105:328-331.

40. Sureda A, Tauler P, Aguiló A, et al. Relation between oxidative stress markers and antioxidant endogenous defences during exhaustive exercise. Free Radical Res. 2005; 39:1317-1324.

41. Margaill I, Plotkine M, Lerouet D. Antioxidant strategies in the treatment of stroke. Free Radical Biol Med. 2005; 39:429-443.

42. Aebi HE. Catalase in vitro. In: Bergmeyer, HU ed. Methods of Enzymatic Analysis. New York: Academic Press; 1983:273-286.

43. Marklund SL. Pyrogallol autooxidation. In: Greenwald RA ed. Handbook of Methods for Oxygen Radical Research. Boca Ratón, FL: CRC Press; 1985:243-247.

44. Boyer SJ, Blume FD. Weight loss and changes in body composition at high altitude. J Appl Physiol. 1984;57: $1580-1585$.

45. Rose MS, Houston CS, Fulco CS, et al. Operation Everest. II: Nutrition and body composition. J Appl Physiol. 1988; 65:2545-2551.

46. Siqués P, Brito J, León-Velarde F, et al. Time course of cardiovascular and hematological responses in rats exposed to chronic intermittent hypobaric hypoxia (4600 m). High Alt Med Biol. 2006;7:72-80.

47. Simler N, Malgoyre A, Koulmann N, et al. Hypoxic stimulus alters hypothalamic AMP-activated protein kinase phosphorylation concomitant to hypophagia. J Appl Physiol. 2007;102:2135-2141.

48. Casas M, Casas H, Pagés T, et al. Intermittent hypobaric hypoxia induces altitude acclimation and improves the lactate threshold. Aviat Space Environ Med. 2000;71: $125-130$.
49. Casas H, Casas M, Ricart A, et al. Effectiveness of three short intermittent hypobaric hypoxia protocols: hematological responses. JEPonline. 2000;3:38-45.

50. LaManna JC, Vendel LM, Farrell RM. Brain adaptation to chronic hypobaric hypoxia in rats. J Appl Physiol. 1992; 72:2238-2243.

51. Rivera-Chira M, León-Velarde F, Huicho L, Monge C. Bone marrow oxygen consumption and erythropoiesis in chronically hypoxic rats. Life Sci. 1994;55:1027-1032.

52. Biljanović-Paunović L, Clemons GK, Ivanović Z, Pavlović-Kentera V. Erythropoietin \& erythroid progenitors in rats exposed to chronic hypoxia. Indian J Med Res. 1996; 104:304-310.

53. Savourey G, Launay JC, Besnard Y, et al. Control of erythropoiesis after high altitude acclimatization. Eur J Appl Physiol. 2004;93:47-56.

54. Row BW, Liu R, Xu W, Kheirandish L, Gozal D. Intermittent hypoxia is associated with oxidative stress and spatial learning deficits in the rat. Am J Respir Crit Care Med. 2003;167:1548-1553.

55. Xu W, Chi L, Row BW, et al. Increased oxidative stress is associated with chronic intermittent hypoxia-mediated brain cortical neuronal cell apoptosis in a mouse model of sleep apnea. Neuroscience. 2004;126:313-323.

56. Behn C, Araneda OF, Llanos AJ, Celedón G, González G. Hypoxia-related lipid peroxidation: evidences, implications and approaches. Respir Physiol Neurobiol. 2007;158: 143-150.

57. Bailey DA, Roukens R, Knauth M, et al. Free radicalmediated damage to barrier function is not associated with altered brain morphology in high-altitude headache. $\mathrm{J} \mathrm{Ce}$ rebral Blood Flow Metab 2006;26:1-3.

58. Teixeira V, Valente H, Casal S, Marques F, Moreira P. Antioxidant status, oxidative stress, and damage in elite trained kayakers and canoeists and sedentary controls. Int J Sport Nutr Exerc Metab. 2009;19:443-456.

59. da Rocha RF, de Oliveira MR, de Bittencourt Pasquali MA, et al. Vascular redox imbalance in rats submitted to chronic exercise. Cell Biochem Funct. 2010;16 [Epub ahead of print].

60. Duthie GG, Robertson JD, Maughan RJ, Morrice PC. Blood antioxidant status and erythrocyte lipid peroxidation following distance running. Arch Biochem Biophys. 1990; 282:78-83.

61. Inayama T, Kumagai Y, Sakane M, Saito M, Matsuda M. Plasma protein-bound sulfhydryl group oxidation in humans following a full marathon race. Life Sci. 1996;59: 573-578.

62. Chen CF, Tsai SY, Ma MC, Wu MS. Hypoxic preconditioning enhances renal superoxide dismutase levels in rats. J Physiol. 2003;552:561-569.

63. Das DK, Maulik N. Cardiac genomic response following preconditioning stimulus. Cardiovasc Res. 2006;70: 254-263. 